\title{
Design of Power Generation Unit Using Roller Mechanism
}

\author{
B. Santosh Sarma ${ }^{1}$, V. Jyothi ${ }^{2}$ D. Sudhir ${ }^{3}$ \\ 1,2,3 (Department of Electronics and Instrumentation Engineering, GITAM University, Visakhapatnam-530045)
}

\begin{abstract}
Now a days the Consumption of power has been increased tremendously. In order to meet the demand of Power by various units various setups has been introduced for effective power generation. In this Project electrical power is being generated as non-conventional method by simply passing vehicles on to the specially designed Roller Setup. This method of Electrical power generation needs no input power. This Project is implemented by using simple drive mechanism such as Roller, some interfaced Electrical components and chain drive Mechanism. The basic principle is simple energy conversion form mechanical to electrical energy by using the vehicles weight (potential energy) \& motion (kinetic energy).Here the process of Electric Power Generation comes under the Mechanism of Electro-Kinetic power Generator. The electro-kinetic power generator is a method of generating electricity by harnessing the kinetic energy of automobiles that drives over the track. The track operates by virtue of a number of specially designed rollers placed on it. When the vehicles pass on the rollers, pressure is exerted on them, which develops the mechanical energy and by means of a specially designed mechanism, a generator is driven, which is capable of producing AC/DC current.
\end{abstract}

Keywords: Kinetic energy, Speed breaker, Electro-mechanical unit, Non-Conventional Energy

\section{Introduction}

Generation of electricity is possible using road track, as vehicles pass over roller mechanism set up electricity can be produced. For reduction of carbon dioxide emission, renewable energies are considered as proper alternative energy [1] .Unlike conventional speed bumps, the roller mechanism set up won't damage the car or waste petrol while driving the car over the rollers. The main advantage is that they produce energy free of charge. The Electro-Kinetic power generator is capable of generating around $10 \mathrm{~kW}$ of electricity which can then be used to power road signs, traffic lights and street lights or stored in batteries for future use. The track is made up of metal rollers that rotate by using the pressure exerted by vehicles passing over it. The movement of the rollers drives a specially developed design, which in turn drives a generator to produce electricity. The repeated rotations from the rollers, which is further attached to another free wheel allowing it to spin freely in-between while vehicles passes over the track. There is a little literature about extraction of kinetic energy from flow of vehicle in the streets. There is so little and invalid literatures in generation of electricity by speed breakers that but the most common approaches can be seen in [2-3] these proposed systems, mostly small radial flux generators with ineffective topologies have been employed. Therefore it is necessary to design a suitable and efficient topology for design of an energy conversion system for extraction of kinetic energy of vehicles.

\subsection{History}

The ramp was invented by Peter Hughes, in the year 2002 an electrical and mechanical engineer who is employed by Highway Energy Systems Ltd. The company says that under normal traffic conditions, the apparatus will produce $30 \mathrm{~kW}$ of electricity. Other proposed applications for the road ramps heating roads in the winter to prevent ice forming and ventilating tunnels to reduce pollution. "The full potential of this is absolutely enormous." Hughes claims that 10 ramps could generate the same power as one wind turbine.

\subsection{Rollers}

\section{Components Used}

The Material which is used is hardened EN8Properties of EN8: EN8 is an unalloyed medium carbon steel with good tensile strength. It is normally supplied in cold drawn or as rolled. Tensile properties can vary but are usually between $500-800 \mathrm{~N} / \mathrm{mm} 2$. EN8 is available from stock in bar and can be cut to your requirements.

Hardening: To be heated uniformly to $830 / 860^{\circ} \mathrm{C}$ until heated through \& Quench in oil or water. Can also be induction or flame hardened. 


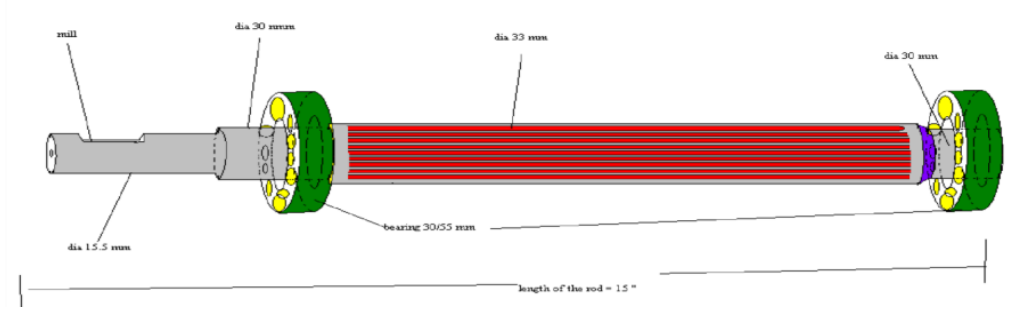

Fig 2.1: Roller which is made with EN8 material

\subsection{BEARINGS}

A bearing is a device to allow constrained relative motion between two or more parts, typically rotation or linear movement. Bearings may be classified broadly according to the motions they allow and according to their principle of operation as well as by the directions of applied loads they can handle. The type of bearing used here is rolling element type bearing which is widely used, relatively high friction, suffers from station in some applications. Depending upon the application, lifetime can be higher or lower than rolling element bearings.

\subsection{Motor as a Generator}

An electrical generator is a device that converts mechanical energy to electrical energy, generally using electromagnetic induction. The source of mechanical energy may be a reciprocating or turbine steam engine, water falling through a turbine or waterwheel, an internal combustion engine, a wind turbine, a hand crank, or any other source of mechanical energy

\section{Roller Mechanism}

In this Mechanism, a roller is fitted in between a speed breaker and some kind of a grip is provided on the speed breaker so that when a vehicle passes over speed breaker it rotates the roller. This movement of roller is used to rotate the shaft of D.C. generator by the help of chain drive which is there to provide different speed ratios. As the shaft of D.C. generator rotates, it produces electricity. This electricity is stored in a battery. Then the output of the battery is used to lighten the street lamps on the road. Now during daytime we don't need electricity for lightening the street lamps so we are using a control switch which is manually operated .The control switch is connected by wire to the output of the battery. The control switch has ON/OFF mechanism which allows the current to flow when needed.

\subsection{Block Diagram}

In this project the ramps has been replaced with the specially designed rollers which directly absorbs the kinetic energy of the moving vehicles and converts them to rotational energy and thereby rotating the generator, to produce the electrical power.
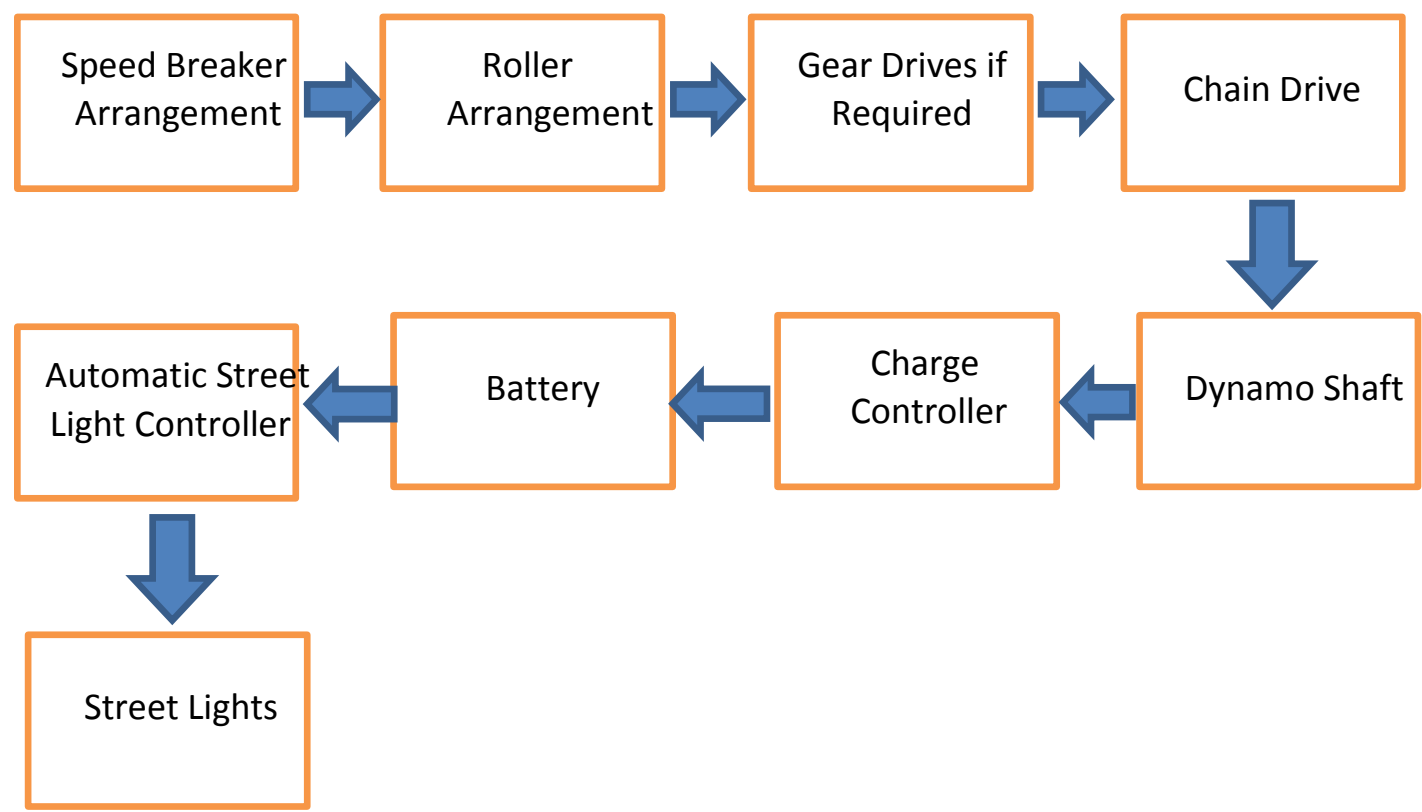

Fig: 1 Block diagram of the setup 


\section{Figures And Tables}

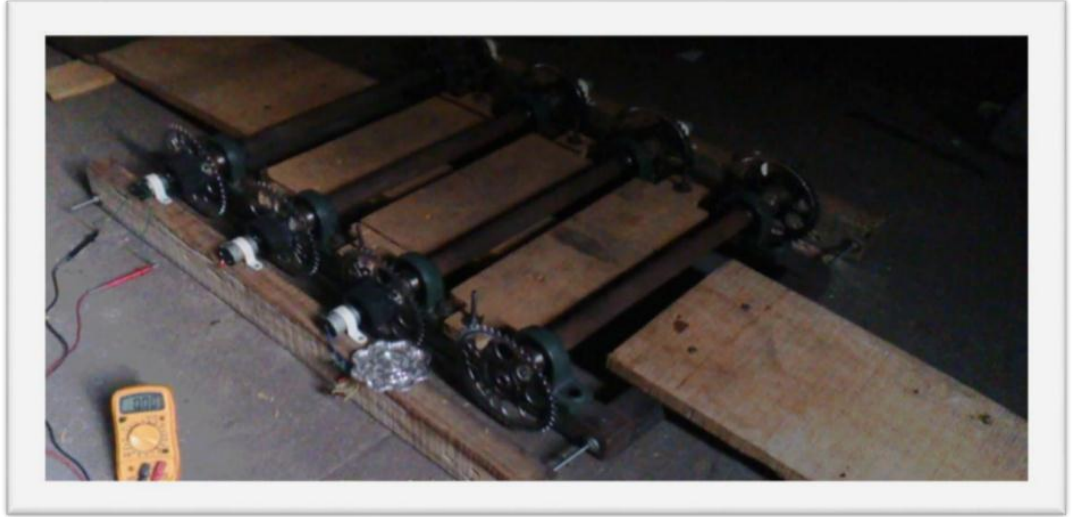

Fig 2: Setup which has made

The figure 2 is the roller mechanism design which was built to generate power from moving vehicles on road. The set up consists of 7DC generators with torque of $5 \mathrm{~kg} 300 \mathrm{rmp}$. The DC generators are fixed to crank connecting the roller.

\section{Dimensions of Roller rode:}

Length $=2$ feet,

Diameter $=40 \mathrm{~mm}$.

Basement dimensions:

Length $=4$ feet,

Width $=1.8$ feet,

Height $=6 \mathrm{~cm}$.

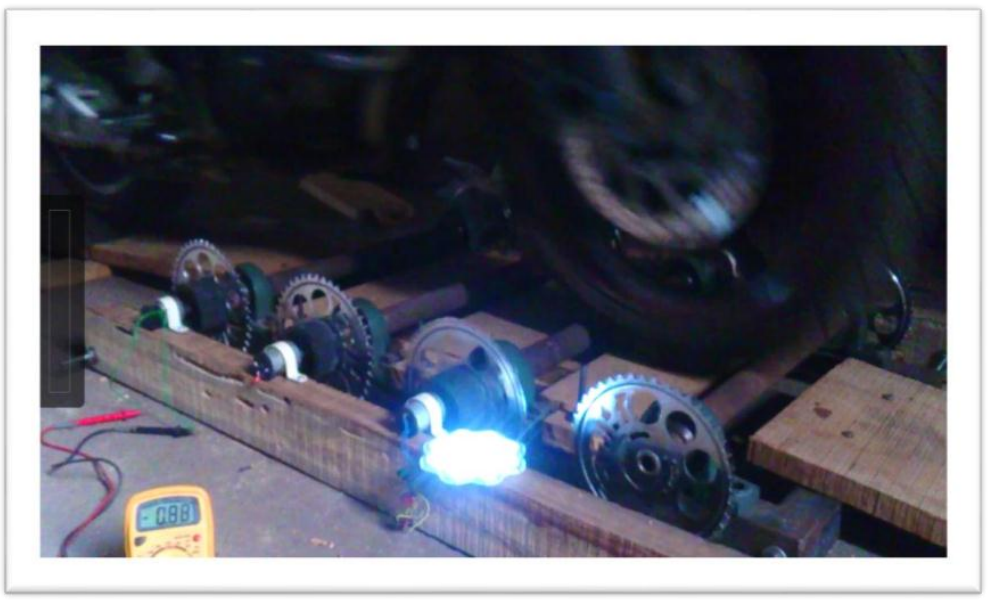

Fig. 3 output from the setup when vehicle passes over it

Initially the set up was run by bike and the roller got the rotatory motion. With that rotation, a single DC generator is able to light up a LED setup of $12 \mathrm{~V}$. Even if there is an anti-direction rotation by the roller, the negative voltage is converted using bridge circuit. The output voltage and current depends on the vehicle weight and speed as the speed of the vehicle decrease the output voltage and current increases the main advantage of the circuit which has used hear holds the reverse flow and the motors which are connected hear are parallel from which we are getting constant voltage but the current has been adding figure 3 shows the output when vehicle passes over it.

The mean power readings has been taken from our consideration as the vehicle with constant load passes on the setup with different speeds the corresponding current and voltage has been taken and plotted the graph between them which is almost linear 


\section{Design of Power Generation Unit Using Roller Mechanism}

Table 1: Mean Power for the vehicle with constant weight

\begin{tabular}{|c|c|c|c|c|}
\hline Sno & Voltage(volts) & current (Amps) & Power(watts) & $\begin{array}{c}\text { Vehicle } \\
\text { weight }\end{array}$ \\
\hline 1 & 4 & 0.17 & 0.68 & 205 \\
\hline 2 & 2 & 0 & 0 & 205 \\
\hline 3 & 0.7 & 0.05 & 0.035 & 205 \\
\hline 4 & 6.3 & 0.6 & 3.78 & 205 \\
\hline 5 & 7.2 & 0.5 & 3.6 & 205 \\
\hline 6 & 4.3 & 0.3 & 1.29 & 205 \\
\hline 7 & 1.4 & 0.1 & 0.14 & 205 \\
\hline 8 & 3.3 & 0.35 & 1.15 & 205 \\
\hline
\end{tabular}

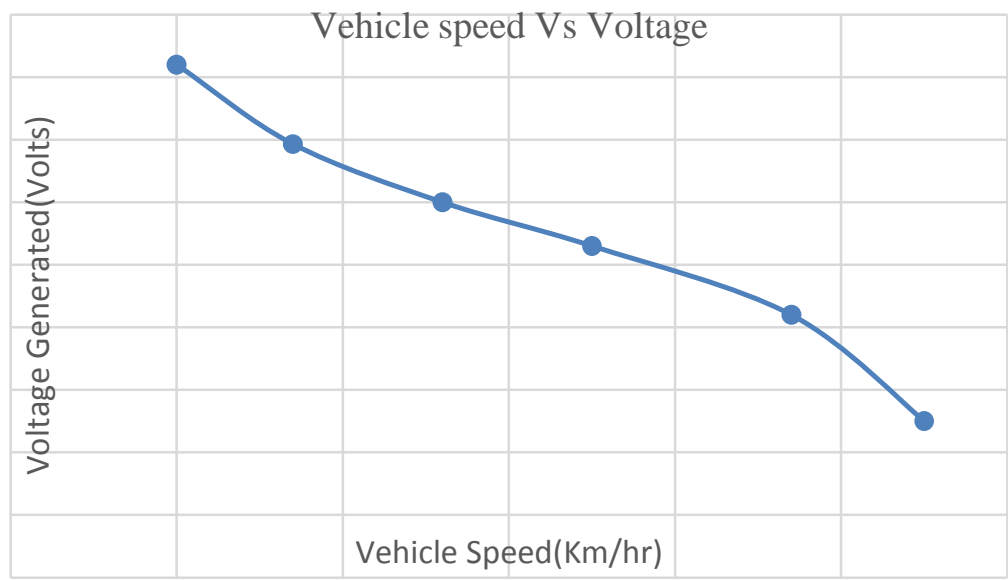

Fig. 4 speed vs voltage

Vehicle speed vs Current(Amps)

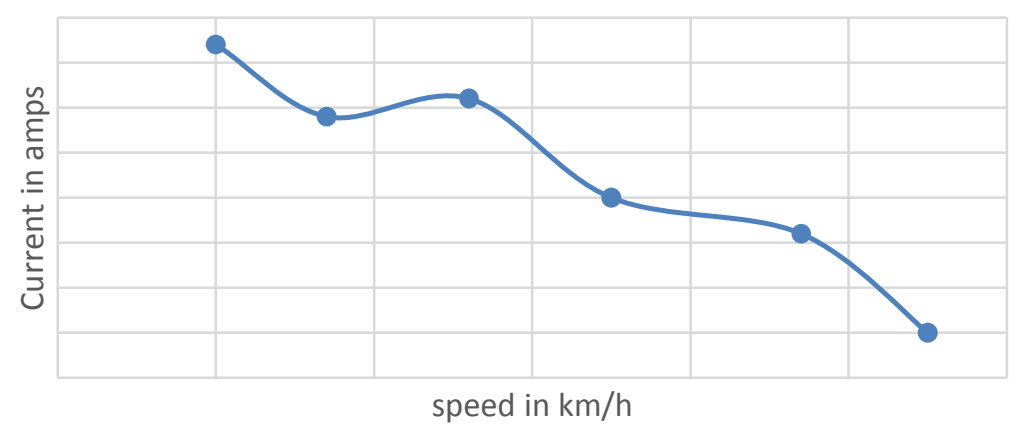

Fig. 5 speed vs current

Table 2: Vehicle load corresponding voltage and current

\begin{tabular}{|c|c|c|}
\hline Load (Kgs) & Voltage(Volts) & current(Amps) \\
\hline 135 & 2.3 & 0.1 \\
\hline 205 & 3.1 & 0.22 \\
\hline 270 & 4.08 & 0.31 \\
\hline 300 & 5.5 & 0.42 \\
\hline 440 & 7.2 & 0.6 \\
\hline 600 & 8.6 & 0.74 \\
\hline
\end{tabular}




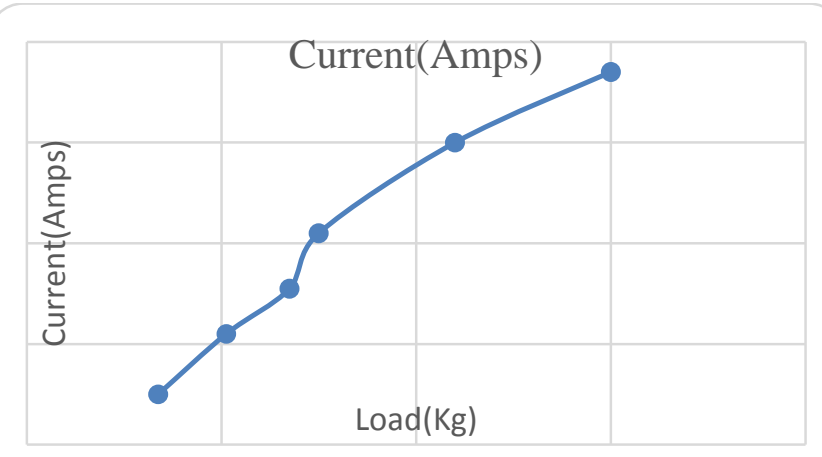

Fig. 6. load vs current

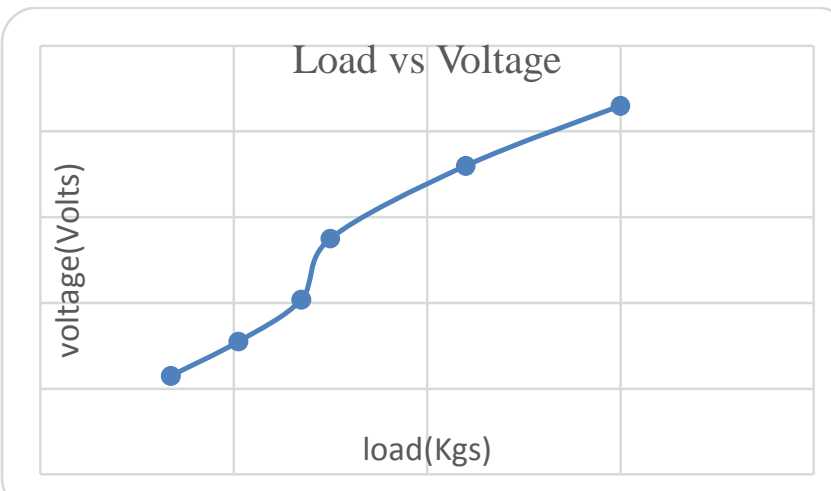

Fig. 7 load vs voltage

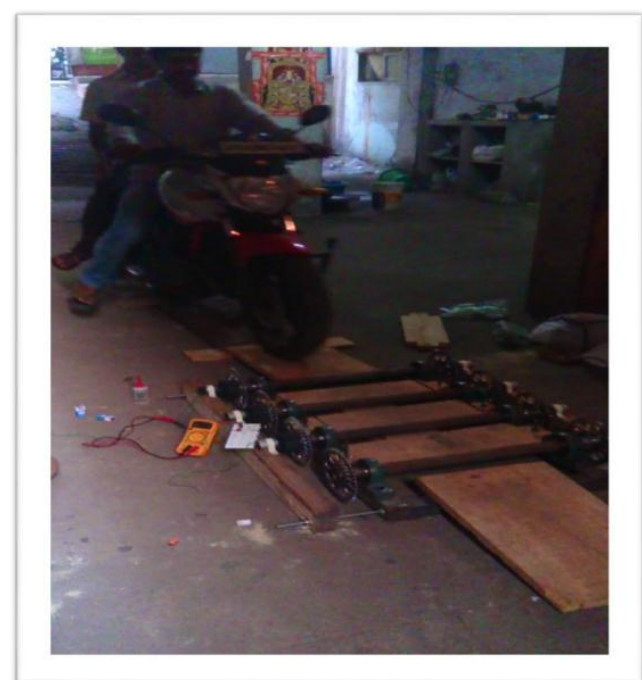

Fig 8: figure shows how vehicle passes on the set up

\subsection{Circuit Diagram}

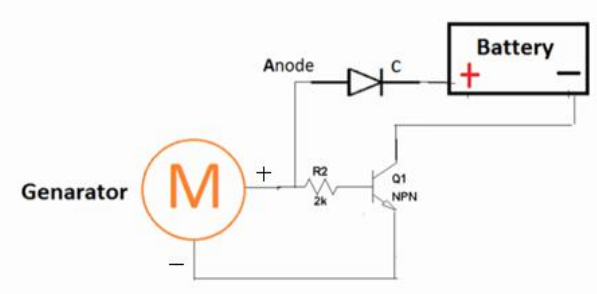

Fig 9 Circuit diagram for individual motors 
Individual motors has connected to the circuit, motor negative has connected to the emitter and positive terminal of motor is connected to diode through which it is connected to the battery here diode acts as rectifier and transistor acts as switch the diode is placed because it stops the reverse flow which makes the motor not to function. The circuit is made for each and every motor and single leads will be connected to the battery for storage

\subsection{Energy Losses}

Energy loss cannot be avoided and is present in each stage, from production to storage. Energy loss happens in the battery in the alternator/dynamo, in the converter (which converts ac to dc), in the voltage regulator. This means that the total energy loss in a pedal powered generator will be about 50-70 \%.[4]

Losses can be minimized by reducing the number of electrical connections and use mechanical connections wherever possible. Considering the cost factor, components of maximum efficiency must be used. Like NiMH batteries can be used as they are the most efficient among the rechargeable batteries.

\section{Calculations For The Power}

The mass of a vehicle moving over the speed breaker $=205 \mathrm{Kg}$ (Approximately)

Height of speed brake $=5 \mathrm{~cm}$

Work done $=$ Force $\mathrm{x}$ Distance

Force $=$ Weight of the Body

Force $=205 \mathrm{Kg} \times$ 9.81(gravity)

Force $=2011.05 \mathrm{~N}$

Distance travelled by the body $=$ Height of the speed brake $=5 \mathrm{~cm}$

Output power $=$ Work done $/ \mathrm{Sec}=(2011.05 \times 0.05) / 60=1.67$ Watts (For One pushing force)

Power developed for 1 vehicle passing over the speed

Breaker arrangement for one minute $=1.67$ watts

Power developed for 60 minutes $(1 \mathrm{hr})=100.2$ watts

Power developed for 24 hours $=2.3 \mathrm{Kw}$

This power is sufficient to burn four street lights in the roads in the night time

\section{Advantages}

Using this technology one can get the following benefits:

- Low maintenance cost

- Low installation cost

- Pollution free power generation.

- No manual work necessary during generation.

- Simple construction, mature technology and easy maintenance.

- No fuel transportation problem.

- Energy available all year round.

- No consumption of any fossil fuel which is non-renewable source of energy.

\section{Conclusion}

No one is happy with present situation of electricity in India. We need electricity for every small thing. More suitable and compact mechanisms to enhance efficiency. So, this is a small step to try to improve this situation by this project and contribute something for the society. Although less electrical output is being generated. The idea of generating electricity from kinetic energy of the moving vehicles has successfully implemented. If this concept is further developed and is produced in high potential

\subsection{Future Scope}

The rollers which are used in this project can be designed for heavy vehicles, thus increasing input torque and ultimately output of generator can also be increased by using the multiple transmission system which is more efficient method for generating electricity

\section{Journal Papers}

\section{References}

[1]. Selvaraj, R.S., Sivamadhavi, V., "Magnitude of Green House Effect and the contribution of Carbon di oxide," Recent Advances in Space Technology Services and Climate Change (RSTSCC), 13-15 Nov. 2010, no. 41 - 44, Chennai.

[2]. Shakun Srivastava, Ankit asthana, "produce electricity by the use of speed breakers," Journal of Engineering Research and Studies, Vol.2, No.1 April-Jun 2011.

[3]. Mukherje, D., Chakrabarti, S., Non-conventional power plants, New Delhi, 2005.

[4]. Pedal Power Generation-International Journal of Applied Engineering Research, ISSN 0973-4562 Vol.7 No.11 (2012) 